\title{
CONDIÇÕES DE TRABALHO E PRECARIZAÇÃO DO ENSINO MÉDIO PÚBLICO ${ }^{1}$
}

TAVARAYAMA, Rodrigo ${ }^{2}$

FERNANDES, Maria Cristina da Silveira Galan ${ }^{3}$

Recebido em: 2009.08.16

Aprovado em: 2010.03.23

ISSUE DOI: $10.3738 / 1982.2278-286$

RESUMO: O objetivo deste trabalho consistiu em analisar o perfil dos professores de geografia e história do Ensino Médio público de duas escolas do interior do estado de São Paulo, tendo como referencial teóricometodológico a perspectiva crítico-dialética, analisando as condições de trabalho dos professores e suas possíveis influências na prática de ensino.

Palavras-chave: Condições de trabalho. Qualidade de ensino. Ensino médio. Prática de ensino.

\section{WORK CONDITIONS AND PRECARITY OF THE PUBLIC HIGH SCHOOLS}

SUMMARY: The objective of this work conssited in analyze the profile of the geography and history teachers from the Public High School from two schools of the state of São Paulo countryside, having as theorical-methodological referencial the critic-dialetic perspective, analyzing the working conditions from the teachers as its possible influences in the educational practices.

Keywords: Working conditions. Education quality. High school. Educational practices.

\section{INTRODUÇÃO}

A educação brasileira tem passado por inúmeros processos de transformações e mudanças nos últimos tempos e estas nem sempre tem sido positivas. Nesse sentido, considerando-se que um dos desafios colocados hoje para a educação consiste em discutir a qualidade da educação brasileira, qualidade esta que vem sendo há tempos questionada, o presente trabalho direciona seu foco para as condições de trabalho que circunscrevem a profissão docente, particularmente de professores de geografia e história do ensino médio público, influenciando diretamente a qualidade do ensino. No entanto, não é possível entender tal questão, sem antes considerar que ela está situada em um contexto maior e que sofre a influência do sistema capitalista de produção.

\footnotetext{
${ }^{1}$ Este artigo apresenta os resultados da dissertação de mestrado defendida no Programa de Pós-graduação em Educação do Centro Universitário Moura Lacerda (PPGE/CUML).

${ }^{2}$ Mestre em Educação. Bacharelado e Licenciado em Ciências Sociais. Prof. FE/FFCL/FAFRAM

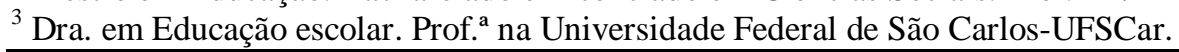


Para Antunes (2006),

A década de 1980 presenciou, nos países de capitalismo avançado, profundas transformações no mundo do trabalho, nas suas formas de inserção na estrutura produtiva, nas formas de representação sindical e política. Foram tão intensas as modificações, que se pode mesmo afirmar que a classe que vive do trabalho sofreu a mais aguda crise deste século, que atingiu não só a sua materialidade, mas teve profundas repercussões na sua subjetividade e, no íntimo inter-relacionamento destes níveis, afetou a sua forma de ser (p.23).

Essas transformações atingiram com maior intensidade os países menos desenvolvidos, o que provocou profundas mudanças políticas, econômicas, culturais e sociais no mundo tornando, assim, necessário o debate em torno do trabalho docente (OLIVEIRA, 2004).

Em meio a esse cenário de mudanças os professores são vistos pela sociedade civil como uma classe detentora de privilégios, o que acaba desprestigiando sua profissão, pois não se leva em consideração as condições de trabalho a que estes profissionais estão sujeitos, salários baixos, salas de aula superlotadas, acúmulo de trabalho e funções (KUENZER, 2004). Segundo Miranda (2005):

Entender a natureza do trabalho docente não passa somente pela análise profunda de
técnicas e procedimentos pedagógicos, do conhecimento como fonte do trabalho, da
relação professor-aluno, mas é necessário, como ponto de partida, compreender que
local de trabalho é a escola e sua relação com a sociedade capitalista contemporânea
(p.4-5).

Nesse sentido é importante compreender que a educação brasileira passa por problemas estruturais no que concerne à capacitação profissional, comprometimento com o conhecimento por parte dos professores e os reflexos das condições de trabalho na prática pedagógica dos professores. Muito se exige dos profissionais da educação, mas em contrapartida não são dadas condições de trabalho necessárias para a execução de suas responsabilidades. Tal situação nos levou a refletir sobre as condições de trabalho a que os professores são submetidos, e o que esses professores pensam em relação a tais condições de trabalho.

O objetivo da pesquisa consistiu, portanto, em identificar e analisar o perfil dos professores da área de humanas do Ensino Médio público, nas disciplinas história e geografia de duas escolas públicas, uma de periferia e outra de um bairro de classe média. Visamos analisar a formação acadêmica dos docentes encontrados nesses dois distintos centros educacionais e suas respectivas condições de trabalho, buscando possíveis relações entre as condições de trabalho dos professores e suas práticas pedagógicas.

Pontuar os desafios e possibilidades do trabalho docente é debater o significado da educação brasileira, um tema polêmico dado a importância do assunto. Nesse sentido, discuti- 
la significa debater parte significativa de nossa realidade educacional, nossas dificuldades e anseios, a fim de melhorar o ensino e promover uma efetiva educação de qualidade.

\section{REFERENCIAL TEÓRICO}

A opção pelo referencial teórico nesse trabalho volta-se para a perspectiva críticodialética. De acordo com Frigotto (1994):

[...] falar da dialética como método de investigação é, ao mesmo tempo, abordar um tema candente e relevante política, ideológica e teoricamente, e, contraditoriamente, expor-se a um conjunto de riscos dos quais o fundamental é o da banalização ou simplificação. (p.71).

Nessa perspectiva levantamos a importância dos fatos históricos para compreender, analisar e refletir sobre a realidade dos professores quanto às suas condições de trabalho. Entendemos que a dialética é contestadora e questionadora da realidade (GADOTTI, 1998). Assim o método dialético de análise tem como princípio apresentar os fatos ao leitor de forma que ele compreenda o fenômeno em sua totalidade e analise as suas contradições (TRIVIÑOS, 1987). A dialética materialista histórica possibilita a compreensão da realidade (da origem ao fim do fenômeno), na busca de mudanças e transformações da mesma e não somente a crítica pela crítica (FRIGOTTO, 1994).

A apreensão da realidade e o processo de conhecimento se dão na práxis, numa reflexão da realidade com objetivo de uma ação transformadora. Pois, não basta somente interpretar a realidade é preciso transformá-la, a teoria e a prática caminham juntas. Assim, a análise dos dados referentes aos professores de história e geografia busca interpretar a realidade com o intuito de poder trazer contribuições para o debate e a qualidade do ensino público no país, visando transformá-lo.

Entendemos que na concepção dialética da realidade nada acontece fora de um contexto social e histórico. Assim, pensar a educação dentro de um contexto social pelo viés dialético significa poder visualizar possibilidades de mudança e transformações do campo educacional e da sociedade. No caso dos professores de história e geografia do ensino médio público possibilita compreender as contradições da prática, os limites das políticas públicas aplicadas à educação, as atuais condições do trabalho docente e o que pensam estes profissionais da educação sobre o seu trabalho.

Nesse sentido, a categoria trabalho é fundamental nessa pesquisa. Ela é frequentemente utilizada em discussões educacionais e sociológicas. E isso já demonstra a sua importância para a compreensão da sociedade capitalista. Marx (1985) conceitua o trabalho 
como sendo a ação que o homem pratica sobre a natureza e esta sobre o homem num movimento espiral dialético. Assim analisar as condições do trabalho docente nas instituições públicas constitui uma importante variável para compreendermos a formação dos professores, a qualidade do ensino e os reflexos desta na prática docente.

Os avanços tecnológicos e científicos, as mudanças no modo de produção capitalista e a globalização trazem transformações e conseqüências na educação, o que implica uma nova formação de professores e novas condições de trabalho. Assim, as propostas de educação são vinculadas aos interesses do capitalismo e é indispensável a correção nos salários, nas condições de trabalho e de exercício profissional para se conseguir uma educação de qualidade e maior motivação por parte dos professores.

Para se ter um ensino de qualidade é preciso ter também professores de qualidade, no entanto, para isso necessita-se de uma política de valorização docente. Como preparar o docente para o seu trabalho? Como demonstrar a dimensão da totalidade em que o problema educacional está mergulhado? Como despertar a práxis criadora, reflexiva e crítica? Qual a dimensão e o significado do trabalho docente?

Libâneo (2007), fundamentado na perspectiva crítica da educação analisa os impactos das transformações econômicas, políticas, sociais, tecnológicas e culturais na educação. Segundo o autor, a escola continua sendo uma instituição necessária à democratização da sociedade. Assim:

É preciso resgatar a profissionalidade do professor, reconfigurar as características de sua profissão na busca da identidade profissional. É preciso fortalecer as lutas sindicais por salários dignos e condições de trabalho. É preciso, junto com isso, ampliar o leque de ação dos sindicatos envolvendo também a luta por uma formação de qualidade, de modo que a profissão ganhe mais credibilidade e dignidade profissional. Faz-se necessário, também, o intercâmbio entre formação inicial e formação continuada, de maneira que a formação dos futuros professores se nutra das demandas da prática e que os professores em exercício freqüentem a universidade para discussão e análise de problemas concretos da prática. (p.10-11)

O mundo globalizado acirra a competição, promove modificações dos padrões de produção e consumo em diferentes campos: econômico, político, social, ético e cultural. Essas mudanças e transformações podem ser positivas, mas também negativas, pois os benefícios são para uma minoria, sobrando para a maioria uma grande lista de exclusão social. Assim também o trabalho do professor é afetado.

$\mathrm{Na}$ perspectiva crítico-dialética é importante que os professores tenham em mente a dimensão e a importância social do seu trabalho para que possam aplicar uma práxis transformadora à sua ação e desvelar o político e o pedagógico num processo dialético. Não há mudança que não ocorra a partir do concreto, da realidade. 
A análise do trabalho docente está situada no cotidiano da ação-prática docente. "É nessa particularidade, no cotidiano da ação docente, que encontramos evidências do saber e do fazer pedagógico do professor que pode se manifestar como uma práxis em seus diversos níveis" (AZZI, 2002, p. 49).

Para Tardif e Lessard (2005) estudar a docência como um trabalho se torna importante pelo contexto que os ofícios e as profissões humanas vêm adquirindo na organização socioeconômica do trabalho, a própria importância da docência hoje na sociedade, as imposições dos modelos educacionais pelo neoliberalismo e a questão da profissionalização do ensino com a análise do trabalho docente. Assim, "longe de ser uma ocupação secundária ou periférica em relação à hegemonia do trabalho material, o trabalho docente constitui uma das chaves para a compreensão das transformações atuais das sociedades do trabalho" (p.17).

Na perspectiva crítico-dialética o professor é um ser pensante não um objeto estático que somente executa ordens. Segundo Azzi (2002), "este pensar reflete o professor enquanto ser histórico, ou seja, o pensar do professor é condicionado pelas possibilidades e limitações pessoais, profissionais e do contexto em que atua" (p.44).

Assim, é importante que se tenha clareza quanto aos desafios da educação nacional, que são muitos, mas é preciso um esforço coletivo, pois dessa forma poderemos avançar no debate e consequientemente na melhoria do quadro educacional brasileiro.

Em síntese podemos afirmar que o referencial crítico-dialético adotado na presente pesquisa apresenta contribuições significativas para a compreensão e discussão das condições de trabalho dos professores entrevistados, evidenciando suas implicações na prática pedagógica.

\section{METODOLOGIA}

A presente pesquisa apresenta caráter qualitativo. De acordo com Triviños (1987), os enfoques qualitativos de pesquisa baseiam-se, fundamentalmente, na fenomenologia e no marxismo. Assim, temos duas abordagens na pesquisa qualitativa, que correspondem a concepções ontológicas e gnosiológicas específicas para se investigar e compreender a realidade:

a) as abordagens subjetivista-compreensivistas, fundamentadas nas idéias de Schleiermacher, Weber, Heidegger, Marcel, Husserl e Sartre entre outros, que privilegiam os aspectos conscienciais, subjetivos dos atores (percepções, processos de conscientização, de compreensão do contexto cultural, da realidade a-histórica, da relevância dos fenômenos de acordo com os significados que os mesmos apresentam para o sujeito); 
b) as abordagens crítico-participativas com visão histórico-estrutural-dialética da realidade social que partem da necessidade de conhecer ( por meio de percepções, reflexão e intuição) a realidade para transformá-la em processos contextuais e dinâmicos complexos. Essa abordagem se fundamenta em Marx, Engels, Gramsci, Adorno, Horkheimer, Marcuse, Fromm, Habermas, sendo tal enfoque o que adotamos em nosso estudo.

A abordagem qualitativa não privilegia, portanto, um modelo único de fazer ciência, pois cada realidade possui a sua própria especificidade. Descrever, compreender e explicar são relações importantes dentro da pesquisa qualitativa, a relação do micro com o macro, do específico com o geral, e as diferentes concepções de mundo na busca de resultados que possam significar mudanças e transformações da realidade.

Segundo Bogdan e Biklen (1994) a abordagem qualitativa possui cinco características: as informações são obtidas através do contato direto do pesquisador com o fenômeno a ser observado, os dados coletados pelo investigador têm caráter descritivo, os investigadores qualitativos se interessam mais pelo processo do que pelos resultados propriamente ditos, a análise dos dados é realizada de forma indutiva e busca-se compreender o significado que os indivíduos pesquisados atribuem as suas experiências.

Entendemos que ao se fazer pesquisa não existe neutralidade científica por parte do pesquisador, mas é importante que se procure manter fiel ao fazer científico, tentando evitar que os preconceitos e crenças possam distorcer a pesquisa. Deve-se considerar, ainda, os limites e os riscos da abordagem qualitativa em educação, a falta de compreensão e definição do referencial teórico pode levar o investigador a uma reflexão exaustiva na tentativa de dar conta de todo o universo que os dados da pesquisa proporcionaram, perdendo, assim, o foco inicial da mesma.

A presente pesquisa foi ainda definida como sendo bibliográfica e de campo. A importância da pesquisa bibliográfica é entendida por Gil (1999), como sendo:

[...] desenvolvida a partir de material já elaborado, constituído principalmente de livros e artigos científicos. Embora em quase todos os estudos seja exigido algum tipo de trabalho desta natureza, há pesquisas desenvolvidas exclusivamente a partir de fontes bibliográficas. Parte dos estudos exploratórios podem ser definidos como pesquisas bibliográficas, assim como certo número de pesquisas desenvolvidas a partir da técnica de análise de conteúdo (p.65).

Antes de sair a campo o pesquisador pode optar por ter um contato prévio com a literatura já produzida sobre o tema de sua pesquisa, para que possa compreender melhor a realidade estudada, contudo essa é uma opção e não uma regra geral. Em nosso estudo, o acesso ao material já produzido em torno do tema de pesquisa permitiu elaborar melhor o 
roteiro de entrevistas, bem como, durante e após a pesquisa de campo, retornar para a pesquisa bibliográfica, buscando novos olhares para a interpretação dos dados coletados.

A pesquisa de campo foi realizada por meio de entrevistas semi-estruturadas. Para Triviños (1987):

[...] a entrevista semi-estruturada mantém a presença consciente e atuante do pesquisador e, ao mesmo tempo, permite a relevância na situação do ator. Este traço da entrevista semi-estruturada [...] favorece não só a descrição dos fenômenos sociais, mas também sua explicação e a compreensão de sua totalidade, tanto dentro de sua situação específica como situações de dimensões maiores (p.152).

A coleta de dados foi realizada em uma cidade do interior do Estado de São Paulo, que recebe muitos professores de outras cidades, os quais denominamos de professores itinerantes, professores que precisam se deslocar de uma cidade e/ou escola para outra para ministrar aulas. Nessa perspectiva, consideramos itinerantes tanto os professores que têm vínculo de cargo efetivo com a rede de ensino em mais de uma escola, cidade, como os profissionais que, independente do grau de vínculo que possuem com as escolas precisam se deslocar para trabalhar.

A questão da itinerância é importante nesse estudo devido a suas implicações e relações com o trabalho do professor, com a qualidade do trabalho e do ensino, fazendo com que os professores tenham que sair de suas cidades para irem trabalhar em outros municípios próximos ou distantes, deixando para trás família e amigos. Outra importante questão ligada à itinerância é a diminuição do número de aulas de história e geografia no ensino médio público, o que obriga os professores a lecionarem em várias escolas para poderem completar a sua carga horária de trabalho.

A coleta de dados foi realizada em duas escolas estaduais da rede de ensino público de Ensino Médio, uma no centro da cidade, considerada de classe média, e uma localizada na periferia, freqüentada pelas camadas populares, visando analisar as duas realidades.

Como o foco da pesquisa era os professores das disciplinas de história e geografia do ensino médio, fizemos o levantamento de dados e verificamos que na Escola $A$ havia três professores ministrando a disciplina de história e três professores na disciplina de geografia. $\mathrm{Na}$ Escola B constatamos a presença de três professores ministrando a disciplina de história e apenas um professor ministrando a disciplina de geografia. No total contávamos, portanto, com dez professores e todos concordaram em participar da pesquisa.

Os dados coletados foram organizados e analisados em quatro categorias principais: Caracterização, Escolha Profissional, Condições de Trabalho e Prática de Ensino, tendo sido analisadas com base no referencial crítico-dialético, conforme se apresenta a seguir. 


\section{PERFIL E CONDIÇÕES DE TRABALHO DE PROFESSORES DE GEOGRAFIA E HISTÓRIA DO ENSINO MÉDIO}

Os dados coletados foram organizados e analisados em 4 (quatro) categorias principais e subcategorias: Caracterização, Escolha Profissional, Condições de Trabalho e Prática de Ensino. Como se observa na tabela abaixo.

\begin{tabular}{|l|l|}
\hline Categoria & Subcategoria \\
\hline Caracterização & $\begin{array}{l}\text { Idade, sexo, estado civil, disciplina } \\
\text { ministrada, formação em instituição } \\
\text { pública ou privada, formação continuada. }\end{array}$ \\
\hline Escolha Profissional & $\begin{array}{l}\text { Influências na escolha pela carreira } \\
\text { docente, família, fator econômico, } \\
\text { exemplos de professores que marcaram sua } \\
\text { história educacional. }\end{array}$ \\
\hline Condições de trabalho & $\begin{array}{l}\text { Precarização, acúmulo e excesso de de } \\
\text { trabalho, classe, itinerância, salário, } \\
\text { progressão continuada, ciclo profissional, } \\
\text { qualidade, recursos pedagógicos. }\end{array}$ \\
\hline Prática docente & $\begin{array}{l}\text { Motivação, autonomia, influência, } \\
\text { capacitações/reciclagem, desvalorização, } \\
\text { socialização das responsabilidades e } \\
\text { saberes docentes. }\end{array}$ \\
\hline
\end{tabular}

Quadro 1. Categorias e subcategorias de análise.

Considerando-se que a caracterização de um grupo social varia de acordo com o contexto social em que é inserido, bem como com as subjetividades de cada indivíduo, Pimenta (2000) e Arroyo (2001) apontam a necessidade de caracterizar e traçar o perfil dos professores como uma variável importante na análise da qualidade do ensino e construção identitária da profissão e do ofício de professor.

Dentre os dez professores entrevistados sete são mulheres e três homens, evidenciando-se ainda o predomínio do sexo feminino na educação (GADOTTI, 2003).

A análise dos dados evidenciou a baixa qualificação dos professores da rede de ensino pública, aliada a não participação em congressos, cursos de extensão, jornadas acadêmicas, etc. Dos dez professores entrevistados, cinco possuíam graduação específica para a disciplina ministrada, um professor concluiu três graduações, três professores apresentavam duas graduações e apenas um docente tinha feito mestrado (curso de pós-graduação Stricto Sensu).

Considerando que a formação de um professor é um processo contínuo, que não se encerra na formação inicial, mas se estende por toda vida profissional é preocupante a realidade nacional em que se verifica o baixo investimento dos professores e governos na carreira docente (BARROS; MENDONÇA; BLANCO, 2001; HUBERMAN, 1995). 
Do número total de entrevistados, três professores residiam na cidade em que a pesquisa foi realizada, enquanto sete professores residiam em outras cidades (itinerantes).

Os dados relativos à faixa etária dos professores possibilitaram constatar que ela varia dos 24 anos aos 53 anos, e observamos que temos professores em início de carreira, final de carreira, início tardio na função docente e um em vias de abandono da profissão (HUBERMAN, 1995).

Os dados coletados permitiram analisar que a maioria dos professores iniciou seus estudos em escolas de ensino fundamental e médio públicas, porém, destes, somente três professores (30\%) fizeram a graduação em instituições de ensino superior públicas e sete professores $(70 \%)$ se graduaram em instituições privadas.

O grande número de professores na rede de ensino formados em instituições particulares se deve principalmente ao fator econômico (MASCARIN, 1999), pois cada vez mais, a população das camadas sociais mais baixas procura cursos de licenciatura por serem mais baratos, o que talvez, possa ser apontado como um dos indícios da baixa qualidade do ensino. Primeiro porque essas camadas sociais chegam às universidades com sérias lacunas de formação básica. E segundo, pela qualidade duvidosa dos cursos oferecidos por certas instituições de ensino privadas (BASSO, 1994).

Conhecer quem são os professores de história e geografia do ensino médio público nos possibilita ter uma dimensão melhor da nossa realidade educacional, dessa forma analisar a escolha pela docência é uma questão que merece atenção e os motivos que levam a esta escolha são diversos (ARROYO, 2001). Nesse sentido, os dados evidenciaram a influência da família, o ideal de educação, o gosto pela profissão, a falta de dinheiro para poder escolher um curso mais elitizado e professores incentivadores possuidores de uma prática docente diferenciada, com quem os professores entrevistados se identificaram.

A qualidade do ensino está diretamente vinculada às condições de trabalho. Nesse sentido, de nada adianta cobrar qualidade sem criar condições reais, concretas para alcançá-la. Pôde-se observar que o trabalho excessivo e exaustivo da atividade docente não atinge somente um grupo ou outro de professores. E algumas vezes os problemas relativos à escola são interiorizados pelos professores e levados para casa (FIALHO, 2005).

Há tempos o trabalho do professor deixou de ser prazeroso e se tornou um trabalho penoso e estressante. Huberman (1995) ao analisar o ciclo de vida dos professores observou as etapas que o professorado vive quanto às suas expectativas e frustrações no decorrer da sua carreira, como entrada, estabilização, diversificação, desinvestimento, dês-motivação e intencionalidade. Essa questão do ciclo de vida professoral está presente também em outros 
trabalhos (FIALHO, 2005; BASSO, 1994). A intensificação do trabalho acaba resultando nos professores o chamado mal estar docente (ESTEVE ZARAGOZA, 1999).

Sobre o acúmulo de trabalho em redes de ensino, constatamos que seis professores (60\%) trabalham somente na rede estadual de ensino, sendo que dois $(20 \%)$ trabalham na rede estadual e particular, um (10\%) na rede estadual e municipal e um $(10 \%)$ trabalha na rede estadual, municipal e particular de ensino, ou seja, $40 \%$ dos docentes acumulam trabalho em mais de uma rede de ensino.

Os dados sobre a questão do acúmulo de trabalho em diferentes redes de ensino evidenciaram duas vertentes de resposta entre os professores. De um lado, alguns professores defendem que para complementar o salário é preciso trabalhar em mais de uma rede de ensino e de outro lado os que assumem que trabalhar em mais de uma rede de ensino acarreta uma queda na qualidade das aulas.

Lança-se um novo desafio hoje: como despertar o interesse e motivar os professores a desenvolverem um trabalho na perspectiva crítica em tempos de crise educacional brasileira? Como motivar o professor, se a cada dia os problemas e os insucessos do campo educacional são atribuídos a eles? Como resgatar a identidade profissional do que é ser professor hoje? Como enfrentar as condições de trabalho precárias? Como inverter a idéia de que tudo fora da escola seja mais interessante do que a sala de aula? Como absorver as novas tecnologias em educação? (CUNHA, 1989).

Observa-se a cada dia uma maior intensificação do trabalho do professor e que este se tornou tão alienante que ele já não é capaz de enxergar as influências na sua prática de ensino. Um conjunto de fatores é responsável por esse processo de alienação que acaba resultando em um processo de desvalorização do professor perante a sociedade, que causa um mal-estar generalizado (ESTEVE ZARAGOZA, 1999), o que foi possível observar nas falas dos professores de história e geografia entrevistados.

Outro ponto importante da análise desta pesquisa diz respeito às influências das condições atuais do trabalho docente na prática pedagógica dos professores, resultando na identificação de fatores que têm contribuído para o fenômeno do mal-estar docente, tais como: o aumento das críticas, a atribuição dos problemas da educação ao professor, interferência de pais e mães no trabalho pedagógico, falta de reconhecimento da importância do trabalho do professor, a crise de identidade profissional, falta de recursos pedagógicos, uma remuneração salarial mais justa e descaso do Estado com a educação. Tais fatores têm colaborado para o aumento da insatisfação dos professores, e se refletido em sua prática docente, como podemos observar na fala da professora P3: 
Reflete, falta motivação, a gente começa empolgado (pensando), está difícil dar aula, não está fácil dar aula, primeiro falta motivação nos professores. [...] Eu estou insatisfeita, tanto é que eu queria prestar outros concursos (ar de desânimo). Está muito sacrificante dar aula (p.3).

Também o deslocamento que os professores realizam todos os dias para poderem trabalhar é uma questão com alto potencial de interferência na prática dos mesmos. Os professores concordam que a itinerância é prejudicial para o ensino, mas nem todos admitem que esse fator esteja interferindo em suas próprias aulas. Tal atitude pode ser interpretada como uma tentativa de autoproteção, desvinculando-se da questão do fracasso educacional, conforme se verifica na fala de P6 que afirma: "Na minha não, independente da questão salarial, da carga horária eu não reduzo a qualidade do momento da aula, eu continuo trabalhando normalmente [...]" (P6).

Entretanto, como afirmam outros professores (P1, P9) e autores (BASSO,1994; FIALHO, 2005), com o passar dos anos na atividade docente as condições de trabalho vão afetando os professores, e essas vão interferindo no seu cotidiano, sendo levadas para dentro da escola e sala de aula, o que, conseqüentemente, contribui para a queda da qualidade do ensino. Se em um determinado momento histórico o trabalho do professor e da escola eram quase inquestionáveis, hoje as ações e interferências, aliadas à falta de apoio da sociedade, do Estado e da própria família vêm causando sérios problemas e transtornos para a escola e seus professores.

Quanto ao deslocamento que os professores necessitam fazer todos os dias para poderem trabalhar pode-se explicitar certo descontentamento por parte deles. De um lado alguns professores afirmam que a itinerância interfere na qualidade do ensino, e de outro lado há profissionais que declaram não deixar que tais condições de itinerância interferiram em suas aulas. Mas é fato que de uma forma ou outra, com o passar dos anos na atividade docente as condições de trabalho vão afetando os professores, e essas vão interferindo no seu cotidiano, sendo levadas para dentro da escola e sala de aula, o que, conseqüentemente, contribui para a queda da qualidade do ensino.

Consideramos que ao assumirem o discurso de que as condições de trabalho não afetam a sua prática de ensino, os professores podem estar tentando desvincular o fracasso educacional da figura do professor.

\section{CONSIDERAÇÕES FINAIS}

Observou-se que a profissão docente vem sofrendo mudanças ao longo do tempo e que essas mudanças, muitas vezes são negativas, criando dois horizontes acerca do que pensam os professores em relação ao seu próprio trabalho. De um lado o que deveria ser o ideal e do 
outro o que vivenciam na prática. Essa contraposição acaba gerando um desconforto ou descontentamento com a profissão. Os sentimentos de culpa provocam sentimentos diversos em relação à educação, que são muitas vezes interiorizados não só na prática profissional como na vida pessoal.

Analisou-se na revisão da literatura que as condições de trabalho precárias têm contribuído para a queda da qualidade do ensino e que tem causado um mal-estar docente generalizado, mas alguns professores entrevistados em nosso estudo negaram que isso ocorresse nas suas práticas e na sua vida. Percebemos que os professores sofrem com a exploração da força do seu trabalho pelo capital. No entanto, o que poderia ser o indício de uma possível transformação e mudança de atitude, numa direção crítica acaba se tornando lamentação e conformismo.

Sobre a socialização das responsabilidades, os professores colocam a culpa dos problemas da educação na família dos alunos, na televisão, internet, celular, progressão continuada, diminuição do número de aulas de história e geografia do ensino médio público que faz com que eles tenham que viver a itinerância todos os dias, deslocando-se por estradas mal pavimentadas, deslocando-se de uma escola para outra. Culpabilizam ainda o Estado, a Escola enquanto instituição e aparelho ideológico do Estado e a sociedade, mas muitas vezes deixam de fazer uma reflexão autocrítica sobre o seu papel no fracasso educacional.

As lacunas abertas pela questão das condições de trabalho, assim, carecem de um horizonte norteador que possa apontar possíveis alternativas de transformações e mudanças. A valorização do professor só irá se efetivar quando este se der conta do contexto em que está inserido e que faça do seu trabalho a sua forma de luta por melhores condições e reconhecimento. Assim, ao analisar o contexto educacional é preciso refletir também sobre a falta de investimentos no setor educacional e seu impacto no trabalho docente.

Nesse sentido o desenvolvimento desse trabalho traz contribuições importantes para o debate em torno das condições de trabalho e da melhoria da qualidade do ensino, levantando diversas questões para o debate educacional.

\section{REFERÊNCIAS}

ANTUNES, R. Adeus ao trabalho? Ensaio sobre as metamorfoses e a centralidade do mundo do trabalho. Campinas: Cortez, 2006.

ARROYO, M. G. Ofício de mestre: Imagens e auto-imagens. Petrópolis, RJ: Vozes, 2001. 
AZZI, S. Trabalho docente: autonomia e construção do saber pedagógico. In: PIMENTA, S. G. (Org.) Saberes pedagógicos e atividade docente. São Paulo: Cortez, 2002. p. 35-60.

BARROS, P. de B., MENDONÇA, R.; BLANCO, M. O mercado de trabalho para professores no Brasil. Associação Nacional dos Centros de Pós-Graduação em Economia (Anpec), p.1-19, 2001. Disponível em: < http://www.anpec.org.br/encontro2001/artigos/200106325.pdf > Acesso em: 24 nov. 2008.

BASSO, I. S. As condições subjetivas e objetivas do trabalho docente: um estudo a partir do ensino de história. 1994. Tese (doutorado) - Programa de Pós-Graduação em Educação. Universidade Estadual de Campinas.

BOGDAN, R.; BIKLEN, S. Características da investigação qualitativa. In: BOGDAN, R.; BIKLEN, S. Investigação qualitativa em educação: uma introdução à teoria e aos métodos. Porto, Portugal: Porto, 1994. p. 47-51.

ESTEVE ZARAGOZA, J. M. O mal-estar docente: a sala de aula e a saúde dos professores. Tradução: Durley de Carvalho Cavicchia. 3 ed. Bauru: Edusc, 1999.

FIALHO, M. N. F. Itinerário profissional e a construção da identidade docente: um estudo a partir de professores de geografia em Belo Horizonte, Minas Gerais, 1950-2005. 2005. Dissertação (mestrado) Programa de Pós-graduação em Educação. Pontifícia Universidade Católica de Minas Gerais.

FRIGOTTO, G. O Enfoque da dialética materialista histórica na pesquisa educacional. In: FAZENDA, Ivani (Org.). Metodologia da pesquisa educacional. São Paulo: Cortez, 1994. p.69-90.

GADOTTI, M. A dialética: concepção e método. In: Concepção dialética da educação: um estudo introdutório. São Paulo: Cortez, 1998. p.15-38.

GADOTTI, M. História das idéias pedagógicas. São Paulo: Ática, 2003.

GIL, A.C. Métodos e técnicas de pesquisa social. São Paulo: Atlas, 1999.

HUBERMAN, M. O ciclo de vida profissional dos professores. In: NÓVOA, A. (Org.). Vidas de professores. Porto: Porto Editora, 1995. p.31-36.

KUENZER, A. Z. Sob a reestruturação produtiva, enfermeiros, professores e montadores de automóveis se encontram no sofrimento do trabalho. Trabalho, educação e saúde. Rio de Janeiro, v. 2, n. 1, p. 239-265, mar, 2004.

LIBÂNEO, J. C. Adeus professor, adeus professora? : novas exigências educacionais e profissão docente. 10. ed. São Paulo: Cortez, 2007.

MARX, K. O Capital: Crítica a economia política. Rio de Janeiro. Difel, 1985. v.1.

MASCARIN, S. R. A produção (trans)formação do professor de geografia: uma experiência teórico-prática na região de campinas (1968-1998). 1999. Dissertação (mestrado) - Programa de Pós-graduação em Educação. Universidade Estadual de Campinas. 
MIRANDA, K. O trabalho docente na acumulação flexível. In: REUNIÃO ANUAL DA ASSOCIAÇÃO NACIONAL DE PÓS-GRADUAÇÃO E PESQUISA EM EDUCAÇÃO, ANEP, 28, Rio de Janeiro, 2005. Disponível em:

<http://www.anped.org.br/reunioes/28/textos/gt09/gt09482int.rtf > . Acesso em: 08 mar.2009.

OLIVEIRA, D. A. A reestruturação do trabalho docente: precarização e flexibilização.

Educação e sociedade, v.25, n.89, p.1127-1144, set./dez. 2004.

PIMENTA, S. G. (Org.). Saberes pedagógicos e atividade docente. São Paulo: Cortez, 2000.

TARDIF, M.; LESSARD, C. O trabalho docente: elementos para uma teoria da docência como profissão de interações humanas. Petrópolis, RJ: Vozes, 2005.

TRIVIÑOS, A. N. S. Introdução à pesquisa em ciências sociais: a pesquisa qualitativa em educação. São Paulo: Atlas, 1987. 